\title{
Chromosomal Mapping of Repetitive DNAs in Characidium (Teleostei, Characiformes): Genomic Organization and Diversification of ZW Sex Chromosomes
}

\author{
Priscilla C. Scacchetti ${ }^{a}$ Ricardo Utsunomia ${ }^{a}$ José C. Pansonato-Alves ${ }^{a}$ \\ Marcelo R. Vicari ${ }^{b}$ Roberto F. Artoni ${ }^{b}$ Claudio Oliveira ${ }^{a}$ Fausto Foresti ${ }^{a}$ \\ a Departamento de Morfologia, Universidade Estadual Paulista, Botucatu, and ${ }^{\mathrm{b}}$ Departamento de Biologia \\ Estrutural, Molecular e Genética, Universidade Estadual de Ponta Grossa, Ponta Grossa, Brazil
}

\section{Key Words}

Chromosome painting - Crenuchidae - Fish cytogenetics .

Karyotype diversification

\begin{abstract}
The speciose neotropical genus Characidium has proven to be a good model for cytogenetic exploration. Representatives of this genus often have a conserved diploid chromosome number; some species exhibit a highly differentiated ZZ/ZW sex chromosome system, while others do not show any sex-related chromosome heteromorphism. In this study, chromosome painting using a W-specific probe and comparative chromosome mapping of repetitive sequences, including ribosomal clusters and 4 microsatellite motifs $(\mathrm{CA})_{15},(\mathrm{GA})_{15},(\mathrm{CG})_{15}$, and $(\mathrm{TTA})_{10}-$, were performed in 6 Characidium species, 5 of which possessed a heteromorphic ZW sex chromosome system. The W-specific probe showed hybridization signals on the W chromosome of all analyzed species, indicating homology among the $\mathrm{W}$ chromosomes. Remarkably, a single major rDNA-bearing chromosome pair was found in all species. The $18 \mathrm{~S}$ rDNA localized to the sex chromosomes in C. lanei, C. timbuiense and C. pterostictum, while the major rDNA localized to one autosome pair in
\end{abstract}

C. vidali and C. gomesi. In contrast, the number of 5S rDNAbearing chromosomes varied. Notably, minor ribosomal clusters were identified in the $\mathrm{W}$ chromosome of $C$. vidali. Microsatellites were widely distributed across almost all chromosomes of the karyotypes, with a greater accumulation in the subtelomeric regions. However, clear differences in the abundance of each motif were detected in each species. In addition, the $\mathrm{Z}$ and $\mathrm{W}$ chromosomes showed the differential accumulation of distinct motifs. Our results revealed variability in the distribution of repetitive DNA sequences and their possible association with sex chromosome diversification in Characidium species. O $2015 \mathrm{~S}$. Karger AG, Basel

Eukaryotic genomes are composed of a substantial amount of repetitive DNA sequences, such as multigene families, microsatellites (or simple sequence repeats; SSRs), and transposable elements, which play important roles in structural genomic organization [López-Flores and Garrido-Ramos, 2012]. In addition, these sequences tend to accumulate in specific chromosomes, including sex chromosomes, primarily because of their nonrecombining nature [Lohe et al., 1993; Kubat et al., 2008; Po-

\section{KARGER 125}

(c) 2015 S. Karger AG, Base

$1424-8581 / 15 / 1462-0136 \$ 39.50 / 0$

E-Mail karger@karger.com

www.karger.com/cgr
Priscilla C. Scacchetti

Departamento de Morfologia, Universidade Estadual Paulista

Distrito de Rubião Junior, s/n

Botucatu, SP 18618-970 (Brazil)

E-Mail pcardim@ibb.unesp.br 
Table 1. Characidium species and populations analyzed

\begin{tabular}{|c|c|c|c|c|c|}
\hline \multirow[t]{2}{*}{ Species } & \multirow[t]{2}{*}{ Coordinates } & \multirow[t]{2}{*}{ Collection sites } & \multirow[t]{2}{*}{ LBP } & \multicolumn{2}{|c|}{ Sample size } \\
\hline & & & & o & $0^{\pi}$ \\
\hline C. cf. zebra & $23^{\circ} 30^{\prime} 40^{\prime \prime} \mathrm{S} 45^{\circ} 51^{\prime} 32^{\prime \prime} \mathrm{W}$ & Paraitinga River, Salesópolis, SP & 8,704 & 3 & 1 \\
\hline C. vidali & $22^{\circ} 28^{\prime} 51.79^{\prime \prime} \mathrm{S} 42^{\circ} 23^{\prime} 39.06^{\prime \prime} \mathrm{W}$ & Bananeiras Stream, Silva Jardim, RJ & 19,039 & 7 & 2 \\
\hline C. gomesi & $23^{\circ} 01^{\prime} 26^{\prime \prime} \mathrm{S} 48^{\circ} 49^{\prime} 32^{\prime \prime} \mathrm{W}$ & Novo River, Avaré, SP & 6,377 & 5 & 3 \\
\hline C. pterostictum & $28^{\circ} 38^{\prime} 43.9^{\prime \prime} \mathrm{S} 53^{\circ} 33^{\prime} 35.7^{\prime \prime} \mathrm{W}$ & Jacuí River, Cruz Alta, RS & 14,672 & 7 & 8 \\
\hline C. timbuiense & $19^{\circ} 58^{\prime} 32.56^{\prime \prime} \mathrm{S} 40^{\circ} 32^{\prime} 53.15^{\prime \prime} \mathrm{W}$ & Valsugana Velha Stream, Santa Teresa, ES & 18,475 & 8 & 7 \\
\hline C. lanei & $25^{\circ} 26^{\prime} 29^{\prime \prime} \mathrm{S} 48^{\circ} 32^{\prime} 28^{\prime \prime} \mathrm{W}$ & Cari River, Morretes, PR & 8,700 & 1 & 2 \\
\hline
\end{tabular}

LBP = Laboratório de Biologia e Genética de Peixes, voucher numbers; ES = Espírito Santo state; PR = Paraná state; RJ = Rio de Janeiro state; RS = Rio Grande do Sul state; SP = São Paulo state.

korná et al., 2011; Kejnovský et al., 2013; Milani and Cabral-de-Mello, 2014; Ruiz-Ruano et al., 2015; Ziemniczak et al., 2014]. In this context, cytogenetic studies have provided a better characterization of sex chromosomes by identifying distinctive degrees of heterochromatinization and differential accumulation of repetitive sequences [for a review, see Cioffi et al., 2010]. Such findings opened opportunities for the examination of sex chromosome homology and origin, investigation of sex chromosome differentiation among congeneric species, and the characterization of putative nascent sex chromosomes [Henning et al., 2008; Vicari et al., 2008; Cioffi and Bertollo, 2010; Schemberger et al., 2011].

Characidium comprises $\sim 70$ valid species widely distributed throughout neotropical rivers [Eschmeyer, 2015]. This group is an excellent model for studies of sex chromosome differentiation because some species present a highly differentiated ZZ/ZW sex system, while others do not have any heteromorphic sex chromosomes. At present, Characidium sex chromosomes are thought to have a single origin, and the proto-sex chromosome was likely NOR bearing [Vicari et al., 2008; Machado et al., 2011; Pansonato-Alves et al., 2014; Pucci et al., 2014]. Subsequently, distinct events such as an increase/decrease in size, NOR translocation and heterochromatinization have shaped sex chromosome diversification in each Characidium species/population [Vicari et al., 2008; Pansonato-Alves et al., 2010, 2011a, b; Machado et al., 2011; Pucci et al., 2014].

In this study, we used a $\mathrm{W}$-specific probe to test the hypothesis of a common sex chromosome origin in 6 Characidium species. In addition, we performed cytogenetic mapping of ribosomal RNA genes and 4 distinct microsatellite motifs to compare the degree of repetitive DNA accumulation on the ZW sex chromosomes with distinct degrees of heterochromatinization. The results obtained here will contribute to a better understanding of rDNA and microsatellite distribution in eukaryotic genomes and will provide insight into diversification of sex chromosomes in Characidium.

\section{Materials and Methods}

\section{Materials and Chromosome Banding}

Six allopatric Characidium species were analyzed, including $C$. cf. zebra, C. gomesi, C. lanei, C. timbuiense, C. vidali, and C. pterostictum (table 1). Cell suspensions from all species were available in our laboratory, and their karyotypes were previously described [Pansonato-Alves et al., 2010, 2011a, b; Scacchetti et al., 2015]. Cbanding procedures were performed as described by Sumner [1972].

\section{Probe Preparation}

Oligonucleotide probes containing microsatellite sequences $(\mathrm{CA})_{15},(\mathrm{GA})_{15},(\mathrm{CG})_{15}$, and (TTA) 10 were directly labeled with TAMRA during synthesis by Sigma, as described by Kubat et al. [2008]. The 5S and 18S rDNA probes were generated by PCR using previously described primers [White et al., 1990; Pendás et al., 1994]. In addition, a W chromosome probe isolated from $C$. gomesi $(\mathrm{CgW})$ was used [Pansonato-Alves et al., 2014]. The 5S rDNA was labeled with biotin-16-dUTP, while the $18 \mathrm{~S}$ rDNA and the $\mathrm{W}$ chromosome probes were labeled with digoxigenin 11dUTP.

\section{Fluorescence in situ Hybridization}

FISH was performed on 2 individuals of each species $(1$ male and 1 female). Cytogenetic mapping of ribosomal sites in C. gomesi and C. cf. zebra was described previously [Pansonato-Alves et al., 2011a, b]. The prehybridization conditions were the same for each sample as described by Pinkel et al. [1986]. Slides were incubated with RNAse $(50 \mu \mathrm{g} / \mathrm{ml})$ for $1 \mathrm{~h}$ at $37^{\circ} \mathrm{C}$, and chromosomal DNA was denatured in $70 \%$ formamide $/ 2 \times \mathrm{SSC}$ for $5 \mathrm{~min}$ at $70^{\circ} \mathrm{C}$. For each slide, $30 \mu \mathrm{l}$ hybridization solution containing $200 \mathrm{ng}$ labeled probe, $50 \%$ formamide, $2 \times$ SSC, and $10 \%$ dextran sulfate was denatured for $10 \mathrm{~min}$ at $95^{\circ} \mathrm{C}$, dropped onto the slides and hybrid- 
ized overnight at $37^{\circ} \mathrm{C}$ in a $2 \times$ SSC moist chamber. Posthybridization washes were performed according to the applied probe: (i) slides probed with ribosomal sites and $\mathrm{CgW}$ were washed in $0.2 \times$ SSC/15\% formamide for $20 \mathrm{~min}$ at $42^{\circ} \mathrm{C}$, followed by a second wash in $0.1 \times \mathrm{SSC}$ for $15 \mathrm{~min}$ at $60^{\circ} \mathrm{C}$, and a final wash at room temperature in $4 \times \mathrm{SSC} / 0.5 \%$ Tween for $10 \mathrm{~min}$; probe detection was performed using avidin-FITC and anti-digoxigenin-rhodamine; (ii) slides probed with oligonucleotides were washed in $2 \times$ SSC for $5 \mathrm{~min}$, followed by a second wash in $1 \times$ PBS for $1 \mathrm{~min}$. Chromosomes were counterstained with DAPI (Vector Laboratories, Burlingame, Calif., USA) and analyzed using an optical photomicroscope (Olympus BX61). Images were acquired using Image Pro Plus 6.0 software (Media Cybernetics, Rockville, Md., USA), and chromosomes were classified as metacentric, submetacentric or acrocentric according to Levan et al. [1964].

\section{Results}

\section{Karyotypes}

The 6 species exhibited an invariable diploid chromosome number of $2 \mathrm{n}=50$, and karyotypes were composed exclusively of bi-armed chromosomes, except C. timbuiense and C. pterostictum, where the karyotypes contained one acrocentric pair (fig. 1).

\section{Microsatellite Distribution and C-Banding}

In general, FISH experiments using the probes $(\mathrm{CA})_{15}$, $(\mathrm{GA})_{15},(\mathrm{CG})_{15}$, and (TTA) 10 showed the same distribution pattern in autosomes with a preferential accumulation in subtelomeric regions, except for the motif $(\mathrm{CG})_{15}$ in C. timbuiense and C. cf. zebra, which apparently was restricted to a single chromosome pair (fig. 1).

C-banding identified the ZW sex chromosomes in all species, except C. cf. zebra (fig. 2). Notably, the sex chromosomes displayed different degrees of heterochromatinization. For example, the C. gomesi W chromosome was almost fully heterochromatic, while the $\mathrm{W}$ chromosome of the remaining species was partially heterochromatic (fig. 2). We observed distinct patterns of SSR distribution on the $\mathrm{Z}$ and $\mathrm{W}$ chromosome of each species. These sequences localized to both euchromatic and heterochromatic areas of the sex chromosomes, including subtelomeric and interstitial regions. We also observed that the C. gomesi W chromosome showed intense accumulation of (TTA) 10 along its entire length (fig. 2).

\section{Ribosomal Probes}

FISH analyses with an $18 \mathrm{~S}$ rDNA probe revealed signals in the subtelomeric regions of the $\mathrm{Z}$ and $\mathrm{W}$ chromosomes of C. timbuiense, C. lanei and C.pterostictum, while the major ribosomal sites were located to one autosomal pair in C. vidali and C. gomesi and in chromosome pair 23 in C. cf. zebra (figs. 2, 3). We observed 5S rDNA probe hybridization signals in 1 autosomal pair of $C$. lanei, and 3 autosomal pairs in C. pterostictum and C. timbuiense. In C. vidali, we detected signals in the $\mathrm{W}$ chromosome and in 1 autosomal pair (figs. 2, 3).

\section{Whole Chromosome Painting}

The CgW probe painted the entire C. gomesi W chromosome and the pericentromeric region of the $\mathrm{Z}$ chromosome. In C. lanei and C. pterostictum, the CgW probe hybridized to the long arm of the $\mathrm{W}$ chromosome and in the pericentromeric region of the $\mathrm{Z}$ chromosome. Finally, the probe painted the long arm of the $\mathrm{W}$ chromosome and the pericentromeric and peritelomeric region of the $\mathrm{Z}$ chromosome of C. vidali (figs. 2, 4).

\section{Discussion}

In this study, we characterized the chromosomal distribution of microsatellite motifs in Characidium. In general, both di- and trinucleotides were widely and similarly distributed in the genomes of the analyzed species, with a preferential accumulation in subtelomeric areas. In fact, it has been postulated that microsatellite accumulation in eukaryotic genomes is nonrandom and that each group of organisms/species show preferential accumulation of specific SSR motifs with a particular chromosomal distribution [Tóth et al., 2000; Ruiz-Ruano et al., 2015]. The $(\mathrm{CA})_{15},(\mathrm{GA})_{15}$ and $(\mathrm{CG})_{15}$ SSRs were previously mapped in different characiform fishes and had similar subtelomeric distributions in Hoplias, Leporinus and Triportheus species, while 2 Semaprochilodus species showed few centromeric/subtelomeric signals [Cioffi et al., 2011, 2012; Poltronieri et al., 2013; Terencio et al., 2013; Yano et al., 2014].

Although there is a clear tendency of SSRs to accumulate in subtelomeric regions of Characidium chromosomes, it must be noted that microsatellite distribution and accumulation in autosomes is susceptible to changes at the interspecies level and at the intragenome level. For example, the $(\mathrm{CG})_{15}$ motif clustered to the subtelomeric

Fig. 1. FISH mapping of microsatellite motifs in Characidium species. Chromosomes were counterstained with DAPI (blue), and microsatellite probes were directly labeled with TAMRA (red). Arrows indicate acrocentric chromosomes. Z, W = Sex chromosomes; B = B chromosomes. Scale bar $=10 \mu \mathrm{m}$.

(For figure see next page.)

Scacchetti/Utsunomia/Pansonato-Alves/ Vicari/Artoni/Oliveira/Foresti 


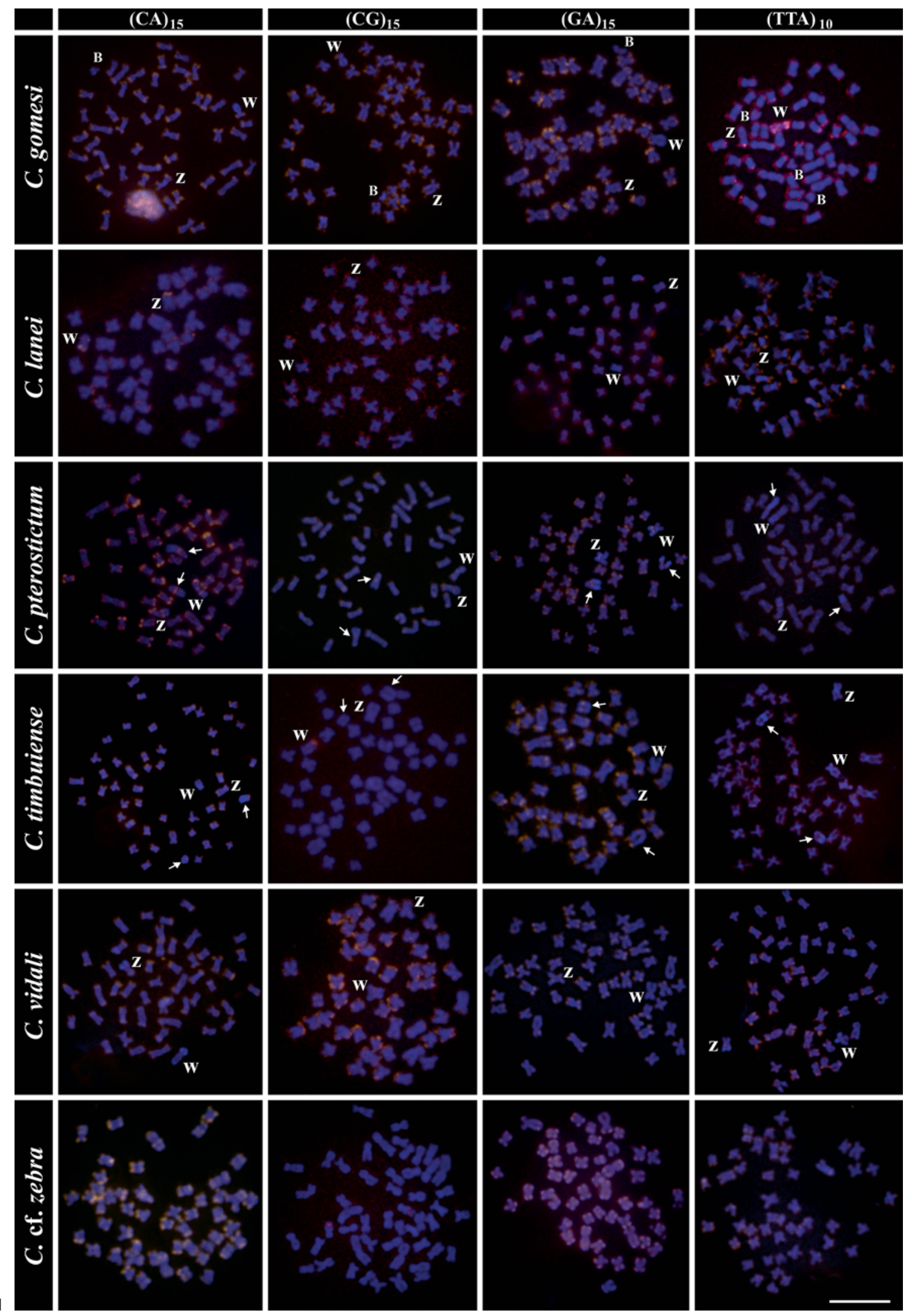


Fig. 2. $\mathrm{Z}$ and $\mathrm{W}$ chromosomes of Characidium species after Giemsa, C-banding and FISH with the CgW probe; $18 \mathrm{~S}$ (red) and $5 \mathrm{~S}$ rDNA (green) probes and microsatellite probes $(\mathrm{CA})_{15},(\mathrm{CG})_{15},(\mathrm{GA})_{15}$, and $(\text { TTA })_{10}$ directly labeled with TAMRA (red).

Fig. 3. Metaphase chromosome plates after FISH with 5 S (green) and $18 \mathrm{~S}$ rDNA (red) probes. $\mathrm{Z}, \mathrm{W}=$ Sex chromosomes. Scale bar $=10 \mu \mathrm{m}$.
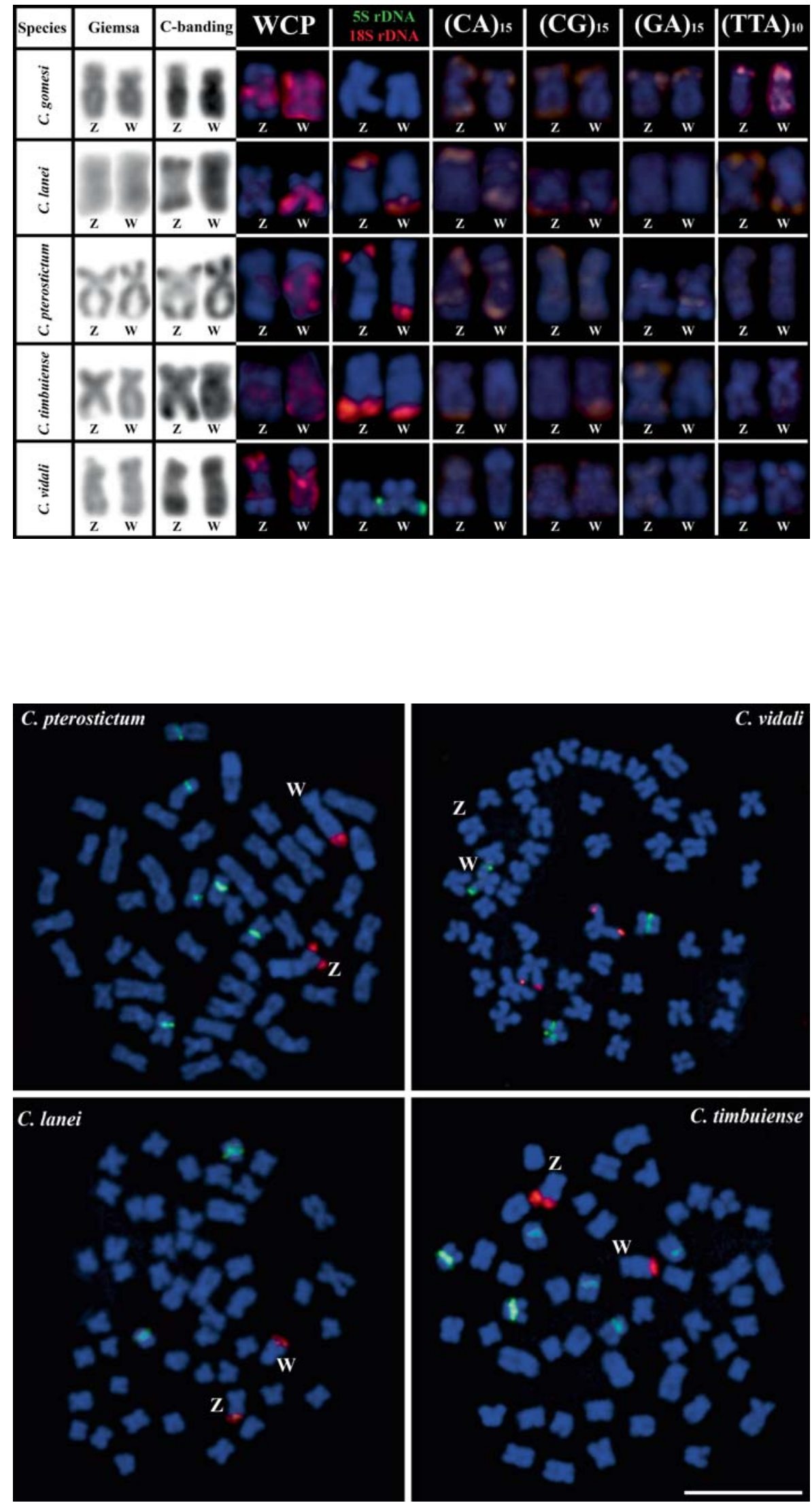
Fig. 4. Metaphase chromosome plates after FISH with $\mathrm{CgW}$ probe. $\mathrm{Z}, \mathrm{W}=$ Sex chromosomes. Scale bar $=10 \mu \mathrm{m}$.
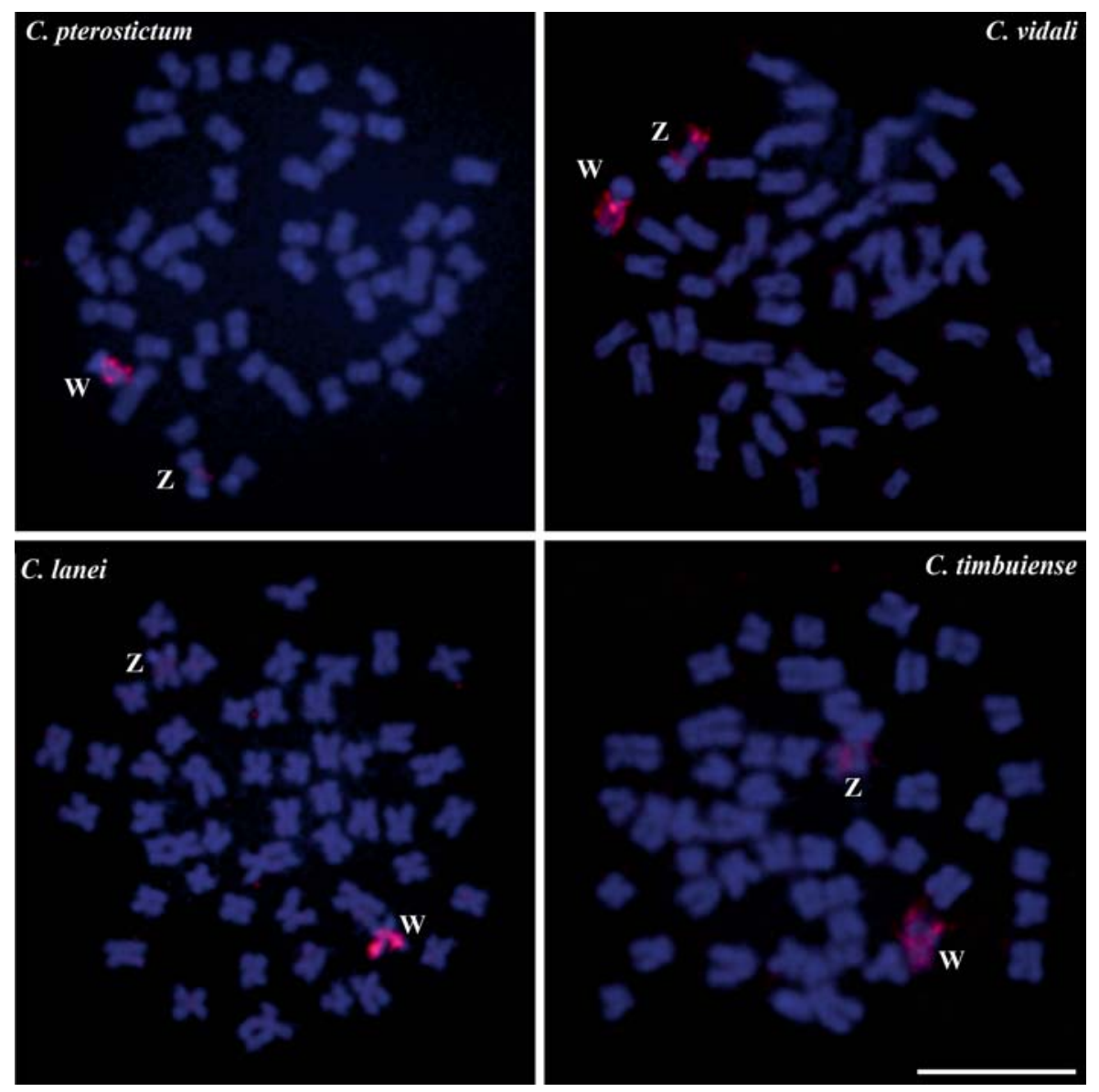

regions of almost all chromosomes in C. gomesi, C. lanei, C. pterostictum, and C. vidali, while the signal was restricted to 1 or 2 chromosomes in C. timbuiense and C. cf. zebra (fig. 1). Because previous studies have shown that C.cf. zebra and C. timbuiense are not closely related species [Buckup, 1993; Vicari et al., 2008; Pansonato-Alves et al., 2014, Scacchetti et al., 2015], we suggest that this specific SSR was partially and independently eliminated from the genomes of both species, suggesting that chromosomal distribution of microsatellite motifs in Characidium does not reflect the evolutionary history of associated taxa. In addition, we observed remarkable interchromosomal differences in SSR abundance. These results are consistent with the idea that SSR genomic organization is governed by distinct molecular mechanisms, including ectopic recombination, unequal crossing-over, slippage replication and association with transposable elements. Together, these mechanisms control the expansion, accumulation and elimination of these sequences at different levels of resolution (e.g. interspecific, interpopula- tional and/or intragenome) [Dover, 1993; McMurray, 1995; Hancock, 1996, Milani and Cabral-de-Mello, 2014; Ruiz-Ruano et al., 2015].

We also investigated the genomic location of minor and major ribosomal DNAs in the C. vidali, C. timbuiense and $C$. lanei species. Our results are consistent with the general patterns of chromosomal distribution of ribosomal genes in genomes of representatives of this genus, with two $18 \mathrm{~S}$ rDNA clusters per genome and variable $5 \mathrm{~S}$ rDNA clusters per genome. Such patterns have been described for several Characidium species, and their dynamics have been attributed to the association with transposable elements [Pucci et al., 2014], as described for many other fish species [da Silva et al., 2011; Silva et al., 2013].

The CgW probe hybridized to the sex chromosomes of the other analyzed species, consistent with the hypothesis that the Characidium ZZ/ZW sex chromosomes are homologous among different species [Machado et al., 2011, Pazian et al., 2013; Pansonato-Alves et al., 2014; Pucci et 
al., 2014]. Although they have been suggested to have a common origin, ZW chromosome diversification in different species is remarkable.

Previous studies have suggested that the presence of $18 \mathrm{~S}$ rDNA sites in Characidium sex chromosomes imply an intermediate degree of heterochromatinization of the $\mathrm{W}$ chromosome. However, if the NOR was translocated to an autosome, the $\mathrm{W}$ chromosome would show a high degree of heterochromatinization [Vicari et al., 2008; Pansonato-Alves et al., 2010; Machado et al., 2011; Pucci et al., 2014]. Such a feature is based on the premise that the NOR-bearing sex chromosomes could still exchange chromosomal segments, thus reducing the rates of evolutionary differentiation. Accordingly, $\mathrm{Z}$ and $\mathrm{W}$ chromosomes without NOR sites would result in decreased recombination frequency and, consequently, favor their differentiation (e.g. the heterochromatinization process) [Pansonato-Alves et al., 2011a, b]. Our results corroborate this hypothesis, with the exception of $C$. vidali, which exhibited Z and $\mathrm{W}$ chromosomes in intermediate stages of heterochromatinization, although they do not display NOR sites. Interestingly, the $C$. vidali $\mathrm{W}$ chromosome also shows an exclusive $5 \mathrm{~S}$ rDNA cluster, which could even further decrease the recombination frequency between heteromorphic chromosomes. Therefore, we hypothesize that NOR translocation occurred more recently in C. vidali than in C. gomesi, and its sex chromosomes are still in the intermediate developmental stages of differentiation. Remarkably, minor ribosomal sequences in the $C$. vidali $\mathrm{W}$ chromosome are highly derived characteristics of this genus, unlike the $18 \mathrm{~S}$ rDNA.

SSR chromosomal mapping revealed well-differentiated ZZ/ZW sex chromosomes in all species with different repetitive DNA class accumulation in distinct regions. For example, some motifs may be more abundant in the $\mathrm{Z}$ chromosome, while others may be exclusively localized to the $\mathrm{W}$ chromosome, such as $(\mathrm{CG})_{15}$ in C. timbuiense. Therefore, we suggest that at a specific period of time, a particular microsatellite might expand and become fixed in the sex chromosomes due to their nonrecombining nature. The lack of consistency for SSR accumulated in the sex chromosomes of different species likely reflects historical contingency as proposed by Pokorná et al. [2011] and should occur stochastically. In all these cases, it is clear that the differential SSR distribution may further decrease the recombination frequency between the $\mathrm{Z}$ and $\mathrm{W}$ chromosomes and, consequently, play a role in their differentiation process.

In general, we did not observe preferential SSR accumulation in $\mathrm{W}$ chromosomes. An exception is C.gomesi, which showed conspicuous (TTA) 10 motif accumulation along the entire $\mathrm{W}$ chromosome length. Coincidently, it is also the only species in our study that exhibited a fully heterochromatic W chromosome, suggesting an association between heterochromatinization and (TTA) 10 accumulation. Consistent with this result, previous studies have shown greater SSR accumulation in the heterochromatic areas of the sex-specific chromosome [Pokorná et al., 2011; Cioffi et al., 2012; Poltronieri et al., 2013; Terencio et al., 2013; Nanda et al., 2014; Yano et al., 2014; Ziemniczak et al., 2014]. However, we found that all other SSRs clustered to either euchromatic or heterochromatic regions of the sex chromosomes, indicating that they are not necessarily associated with heterochromatin accumulation.

In the present study, the large diversity of SSR chromosomal distribution patterns in Characidium species provides new evidence for the intense and continuous genomic changes in closely related species of the genus. Our data also provide additional information about the association of repetitive sequences with sex chromosome evolution in Characidium. Finally, our results support the idea that random and specific events, and not intrinsic features of a particular sequence, play a major role in determining which SSR will accumulate in genomes of each species.

\section{Acknowledgments}

This study was supported by the Fundação de Amparo à Pesquisa do Estado de São Paulo (FAPESP), Coordenadoria de Aperfeiçoamento de Pessoal de Nível Superior (CAPES) and Conselho Nacional de Desenvolvimento Científico e Tecnológico (CNPq) from Brazil.

References

Buckup PA: Phylogenetic interrelationships and reductive evolution in neotropical characidiin fishes (Characiformes, Ostariophysi). Cladistics 9:305-341 (1993).

-Cioffi MB, Bertollo LAC: Initial steps in XY chromosome differentiation in Hoplias malabaricus and the origin of an $\mathrm{X}_{1} \mathrm{X}_{2} \mathrm{Y}$ sex chromosome system in this fish group. Heredity (Edinb) 105:554-561 (2010).

Cioffi MB, Camacho JPM, Bertollo LAC: Repetitive DNAs and differentiation of sex chromosomes in Neotropical fishes. Cytogenet Genome Res 132:188-194 (2010).

Cioffi MB, Kejnovský E, Bertollo LAC: The chromosomal distribution of microsatellite repeats in the genome of the wolf fish Hoplias malabaricus, focusing on the sex chromosomes. Cytogenet Genome Res 132:289-296 (2011).

Scacchetti/Utsunomia/Pansonato-Alves/ Vicari/Artoni/Oliveira/Foresti 
Cioffi Mde B, Kejnovský E, Marquioni V, Poltronieri J, Molina WF, et al: The key role of repeated DNAs in sex chromosome evolution in two fish species with ZW sex chromosome system. Mol Cytogenet 5:42 (2012).

Dover GA: Evolution of genetics redundancy for advanced player. Curr Opin Genet Dev 3: 902-910 (1993).

Eschmeyer WN: Catalog of Fishes: Genera, Species, References. http://researcharchive. calacademy.org/research/ichthyology/catalog/fishcatmain.asp (accessed April 4, 2015).

Hancock JM: Simple sequences and the expanding genome. Bioessays 18:421-425 (1996).

Henning F, Trifonov V, Ferguson-Smith MA, de Almeida-Toledo LF: Non-homologous sex chromosomes in two species of the genus Eigenmannia (Teleostei: Gymnotiformes). Cytogenet Genome Res 121:55-58 (2008).

Kejnovský E, Michalovova M, Steflova P, Kejnovska I, Manzano S, et al: Expansion of microsatellites on evolutionary young $\mathrm{Y}$ chromosome. PLoS One 8:e45519 (2013).

Kubat Z, Hobza R, Vyskot B, Kejnovský E: Microsatellite accumulation on the Y chromosome of Silene latifolia. Genome 51:350-356 (2008).

- Levan A, Fredga K, Sandberg AA: Nomenclature for centromeric position on chromosomes. Hereditas 52:201-220 (1964).

Lohe AR, Hilliker AJ, Roberts PA: Mapping simple repeated DNA sequences in heterochromatin of Drosophila melanogaster. Genetics 134:1149-1174 (1993).

López-Flores I, Garrido-Ramos MA: The repetitive DNA content of eukaryotic genomes, in Garrido-Ramos MA (ed): Repetitive DNA. Genome Dyn, vol 7, pp 1-28 (Karger, Basel 2012).

-Machado TC, Pansonato-Alves JC, Pucci MB, Nogaroto V, Almeida MC, et al: Chromosomal painting and ZW sex chromosomes differentiation in Characidium (Characiformes, Crenuchidae). BMC Genet 12: 65 (2011).

McMurray CT: Mechanisms of DNA expansion. Chromosoma 104:2-13 (1995).

-Milani D, Cabral-de-Mello DC: Microsatellite organization in the grasshopper Abracris flavolineata (Orthoptera: Acrididae) revealed by FISH mapping: remarkable spreading in the $\mathrm{A}$ and B chromosomes. PLoS One 9:e97956 (2014).

-Nanda I, Schories S, Tripathi N, Dreyer C, Haaf $\mathrm{T}$, et al: Sex chromosome polymorphism in guppies. Chromosoma 123:373-383 (2014).

- Pansonato-Alves JC, Paiva LRS, Oliveira C, Foresti F: Interespecific chromosomal divergences in the genus Characidium (Teleostei: Characiformes: Crenuchidae). Neotrop Ichythyol 8:77-86 (2010).
Pansonato-Alves JC, Vicari MR, Oliveira C, Foresti F: Chromosomal diversification in samples of Characidium cf. gomesi (Teleostei, Crenuchidae). J Fish Biol 78:183-194 (2011a).

-Pansonato-Alves JC, Oliveira C, Foresti F: Karyotypic conservatism in samples of Characidium cf. zebra (Teleostei, Characiformes, Cre nuchidae): physical mapping of ribosomal genes and natural triploidy. Genet Mol Biol 34:208-213 (2011b).

Pansonato-Alves JC, Serrano ÉA, Utsunomia R, Camacho JPM, Costa-Silva GJ, et al: Single origin of sex chromosomes and multiple origins of B chromosomes in fish genus Characidium. PLoS One 9:e107169 (2014).

Pazian MF, Shimabukuro-Dias CK, PansonatoAlves JC, Oliveira C, Foresti F: Chromosome painting of $\mathrm{Z}$ and $\mathrm{W}$ sex chromosomes in Characidium (Characiformes, Crenuchidae). Genetica 141:1-9 (2013).

Pendás AM, Moran P, Freije JP, Garcia-Vazquez E: Chromosomal mapping and nucleotide sequence of two tandem repeats of Atlantic salmon 5S rDNA. Cytogenet Cell Genet 67: 31-36 (1994).

Pinkel D, Straume T, Gray JW: Cytogenetic analysis using quantitative, high-sensitivity, fluorescence hybridization. Proc Natl Acad Sci USA 83:2934-2938 (1986).

Pokorná M, Kratochvíl L, Kejnovský E: Microsatellite distribution on sex chromosomes at different stages of heteromorphism and heterochromatinization in two lizard species (Squamata: Eublepharidae: Coleonyx elegans and Lacertidae: Eremias velox). BMC Genet 12:90 (2011).

Poltronieri J, Marquioni V, Bertollo LAC, Kejnovský E, Molina WF, et al: Comparative chromosomal mapping of microsatellites in Leporinus species (Characiformes, Anostomidae): unequal accumulation on the W chromosomes. Cytogenet Genome Res 142: 40-45 (2013).

Pucci MB, Barbosa O, Nogaroto V, Almeira MC, Artoni RF, et al: Population differentiation and speciation in the genus Characidium (Characiformes: Crenuchidae): effects of reproductive and chromosomal barriers. Biol J Linn Soc 111:541-553 (2014).

Ruiz-Ruano FJ, Cuadrado Á, Montiel EE, Camacho JPM, López-León MD: Next generation sequencing and FISH reveal uneven and nonrandom microsatellite distribution in two grasshopper genomes. Chromosoma 124: 221-234 (2015).

Scacchetti PC, Utsunomia R, Pansonato-Alves JC, Costa-Silva GJ, Oliveira C, Foresti F: Extensive spreading of interstitial telomeric sites on the chromosomes of Characidium (Teleostei, Characiformes). Genetica 143:263-270 (2015).
Schemberger MO, Bellafronte E, Nogaroto V, Almeida MC, Schühli GS, et al: Differentiation of repetitive DNA sites and sex chromosome systems reveal closely related group in Parodontidae (Actinopterygii: Characiformes). Genetica 139:1499-1508 (2011).

da Silva M, Matoso DA, Vicari MR, Almeida MC, Margarido VP, Artoni RF: Physical mapping of $5 \mathrm{~S}$ rDNA in two species of Knifefishes: Gymnotus pantanal and Gymnotus paraguensis (Gymnotiformes). Cytogenet Genome Res 134:303-307 (2011).

Silva DMZA, Pansonato-Alves JC, Utsunomia R, Daniel SN, Hashimoto DT, et al: Chromosomal organization of repetitive DNA sequences in Astyanax bockmanni (Teleostei, Characiformes): dispersive location, association and co-localization in the genome. Genetica 141:329-336 (2013).

Sumner AT: A simple technique for demonstrating centromeric heterochromatin. Expl Cell Res 75:304-306 (1972).

Terencio ML, Schneider CH, Gross MC, Vicari MR, Farias IP, et al: Evolutionary dynamics of repetitive DNA in Semaprochilodus (Characiformes, Prochilodontidae): a fish model for sex chromosome differentiation. Sex Dev 7: 325-333 (2013).

Tóth G, Gáspári Z, Jurka J: Microsatellites in different eukaryotic genomes survey and analysis. Genome Res 10:967-981 (2000).

Vicari MR, Artoni RF, Moreira-Filho O, Bertollo LAC: Diversification of a ZZ/ZW sex chromosome system in Characidium fish (Crenuchidae, Characiformes). Genetica 134:311317 (2008).

Yano CF, Poltronieri J, Bertollo LAC, Artoni RF, Liehr T, Cioffi MB: Chromosomal mapping of repetitive DNAs in Triportheus trifurcatus (Characidae, Characiformes): insights into the differentiation of the $\mathrm{Z}$ and $\mathrm{W}$ chromosomes. PLoS One 9:e90946 (2014).

White TJ, Bruns T, Lee S, Taylor L: Amplification and direct sequencing of fungal ribosomal RNA genes for phylogenetics, in Innis MA, Gelfand DH, Sninsky JJ, White TJ (eds): PCR Protocols: A Guide to Methods and Applications, pp 312-315 (Academic Press Inc, London/New York 1990).

Ziemniczak K, Traldi JB, Nogaroto V, Almeida MC, Artoni RF, et al: In situ localization of (GATA)n and (TTAGGG)n repeat DNAs and $\mathrm{W}$ sex chromosome differentiation in Parodontidae (Actinopterygii: Characiformes). Cytogenet Genome Res 144:325-332 (2014). 